\title{
BMJ Global Health The effectiveness of maternity waiting homes in reducing perinatal mortality: a case-control study in Ethiopia
}

To cite: Dalla Zuanna T,

Fonzo M, Sperotto M, et al. The effectiveness of maternity waiting homes in reducing perinatal mortality: a case-control study in Ethiopia. BMJ Global Health 2021;6:e004140. doi:10.1136/ bmjgh-2020-004140

Handling editor Valery Ridde

Received 15 0ctober 2020 Revised 19 March 2021 Accepted 31 March 2021
Check for updates

C) Author(s) (or their employer(s)) 2021. Re-use permitted under CC BY-NC. No commercial re-use. See rights and permissions. Published by BMJ.

${ }^{1}$ Hygiene and Public Health Unit, Department of Cardiac Thoracic and Vascular Sciences and Public Health, University of Padua, Padua, Italy

${ }^{2}$ Saint Luke Hospital, Wolisso, Ethiopia

${ }^{3}$ Addis Ababa Coordination Office, Doctors with Africa CUAMM, Addis Ababa, Ethiopia ${ }^{4}$ Headquarters, Doctors with Africa CUAMM, Padua, Italy

Correspondence to Dr Marco Fonzo; marco.fonzo@unipd.it

\section{ABSTRACT}

Background The 2030 Agenda for Sustainable Development aims to reduce neonatal mortality to at least 12 per 1000 live births. Most of the causes can be prevented or cured. Access to quality healthcare during pregnancy and labour is the key to reduce perinatal deaths, and maternity waiting homes (MWHs) may have an impact, especially for women who live far from the healthcare system. We conducted a case-control study to evaluate the effectiveness of MWH in reducing perinatal mortality in a secondary hospital in Ethiopia.

Methods We did a nested case-control study from January 2014 through December 2017. The enrolled cases were mothers whose childbirth resulted in stillbirth or early neonatal death. The controls were mothers with an alive baby at 7 days or with an alive baby on discharge. We collected demographic, anamnestic, pregnancy-related and obstetric-related data. The effectiveness of the MWH on perinatal death was assessed by a logistic regression model, adjusted for all other variables investigated as potential confounders. We also did a sensitivity analysis to explore the role of twin pregnancies.

Results We included 1175 cases and 2350 controls. The crude analysis showed a protective effect of the MWH towards perinatal mortality $(\mathrm{OR}=0.700 ; 95 \% \mathrm{Cl}: 0.505$ to 0.972$)$, even more protective after adjustment for confounders (adjusted OR $(A O R)=0.452 ; 95 \% \mathrm{Cl}: 0.293$ to 0.698$)$. Sensitivity analyses showed a consistent result, even excluding twin pregnancies (AOR=0.550; $95 \%$ Cl: 0.330 to 0.917).

Conclusion MWHs appear to reduce perinatal mortality by $55 \%$. Our findings support the decision to invest in MWH to support pregnant women with higher quality and more comprehensive healthcare strategy, including quality antenatal care in peripheral primary care clinics, where risk factors can be recognised and women can be addressed for admission to MWH.

\section{INTRODUCTION}

The 2030 Agenda for Sustainable Development aims to reduce the neonatal mortality below 12 deaths per 1000 live births by $2030 .{ }^{1}$ The Alliance for Maternal and Newborn Health Improvement mortality study group estimated in 2012-2016 a neonatal mortality rate of 20.1 (14.6-27.6 per 1000 live births) and a stillbirth rate of 17.1 (12.525.8 per 1000 live births) in sub-Saharan Africa. ${ }^{2}$

\section{Key questions}

What is already known?

- Although the 2030 Agenda for Sustainable Development aims to reduce perinatal mortality to at least 12 deaths per 1000 live births, this goal is likely to be difficult to achieve in sub-Saharan Africa — even if most causes are preventable or curable.

- Access to quality healthcare during pregnancy and childbirth is of paramount importance and maternity waiting homes (MWHs) may have an impact in this context, especially for people far from the healthcare system.

- The quality of the available evidence in this regard has been so low that in 2015 the WHO gave only a conditional recommendation for the implementation of MWHs, expressing the need for studies with a more robust design

What are the new findings?

- This study is the first case-control study that evaluates the effectiveness of hospital MWHs in reducing perinatal mortality in a low-to-middle-income country.

- In our study, the risk of perinatal mortality among MWHuser mothers was half of non-users (adjusted OR: 0.452, $95 \%$ Cl: 0.293 to 0.698 ), showing the effectiveness of this tool in the struggle against perinatal mortality.

- We investigated a number of maternal, obstetrical and neonatal factors as confounding variables: many disorders associated with stillbirths often coexist and adjustment for these factors is essential to understand the role of a specific intervention.

- In our study, we evaluated the effectiveness of the MWH including also twin births while in previous studies twin births have often been ruled out from the analysis.

Public health programmes need to further intensify the delivery of effective interventions to reduce perinatal deaths, since most causes are potentially preventable or treatable. ${ }^{3}$ Obstetric haemorrhage, non-obstetric complications, hypertension in pregnancy and pregnancy-related infections account for more than three-quarters of stillbirths. The most common causes of neonatal deaths are perinatal asphyxia and severe neonatal infections, followed by complications of preterm birth. ${ }^{2}$ 


\section{Key questions}

What do the new findings imply?

- These characteristics are a strength of this study and go in the direction advocated by the WHO recommendations for improving scientific evidence in similar contexts.

- Our results add to the evidence that the MWH is effective in reducing perinatal mortality, although MWH users show more risk factors, some of which-including twin pregnancy-are clearly involved in driving the decision whether to be admitted to the MWH.

- This study has a number of variables that have been studied so that it may be useful in drawing up priority criteria for admission to $\mathrm{MWH}$ on a national basis, supporting the decision to invest in MWH and to provide pregnant women with more comprehensive and skilled healthcare.

The access to quality healthcare during pregnancy, labour, delivery and the neonatal period will be the key to achieve reductions in preventable perinatal deaths especially in case of high-risk pregnancies. ${ }^{4}$ Maternity waiting homes (MWHs) may have an impact especially for populations who live far from health system, considering that $40 \%-45 \%$ of perinatal deaths occur during labour, delivery and the 24-hour post partum. ${ }^{25}$ An MWH is a facility with easy possibility of reaching a hospital or health centre which provides emergency obstetric care. Women are admitted to an $\mathrm{MWH}$ to await labour, with the aim of breaking down barriers to access such as distance, unfavourable seasonal climate, lack of infrastructures and means of transportation, cost of transport and inefficient communication between referral points. ${ }^{6}$

Some studies showed a favourable effect of the MWH on the outcomes for both women and newborns. ${ }^{67}$ However, in 2012 the Cochrane review concluded that there had been insufficient evidence on the benefit of $\mathrm{MWH}$ to unequivocally recommend these facilities. ${ }^{7}$ In 2015 , the $\mathrm{WHO}$ gave a conditional recommendation for implementing MWHs given the very low quality of available evidence. ${ }^{6}$ In 2017, Buser and Lori reiterated the need to generate further evidence on the effectiveness of MWHs on newborn outcomes in lowresource settings. ${ }^{8}$

Starting from the 1960s and during the last decades of the 20th century, many low-income and middle-income countries, including Ethiopia, have implemented MWHs as part of a national programme, with the aim of reducing perinatal and maternal mortality. In Ethiopia between 2011 and 2016, the perinatal death rate was 33 per 1000 live births. ${ }^{9}$ Previous studies conducted in Ethiopia found MWHs to be effective in the reduction of perinatal mortality at hospital level. ${ }^{10-12}$ All of them were cross-sectional and did not adjust for confounding factors. In this perspective study, we conducted a nested case-control study with the aim to evaluate the effectiveness of the MWH in reducing perinatal mortality in a secondary hospital in Ethiopia.

\section{METHODS}

Context

The Saint Luke Hospital (SLH) is a private not-for-profit hospital, accredited by the Oromiya public health system. It is in Wolisso and serves as the zonal hospital for the South West Shoa Zone (SWSZ, catchment area of 1223311 inhabitants in 2017). It is the referral hospital of the three primary hospitals of Ameya, Bantu and Tullu Bolo). The financial support is provided by the Oromiya Region $(13.0 \%)$, the Italian nongovernmental organisation (NGO) 'Doctors With Africa CUAMM' (35.0\%), users' fees $(35.0 \%)$ and other donors $(17.0 \%)$. The fees for delivery services were kept low by decision of the Board of Governors, and further reduced thanks to the financial support through the CUAMM's project 'Mothers and children first'.

In the SLH, 24 beds in the maternity ward are available for mothers before and immediately after delivery (6 hours or longer if complications occur). The delivery room is provided with six labour and three delivery beds, with a 24/7 obstetric assistance (during the night on call) by midwives, graduated in a 3-year midwifery school. A gynaecologist manages the ward, helped in the operating room by a health officer (health personnel with 5-year training) with a specialisation in emergency obstetric and general surgery. The SLH is the only hospital in the SWSZ which provides $24 / 7$ a comprehensive emergency obstetric and neonatal care assistance, which also includes the performance of caesarean sections and blood transfusions. In 2017, 4300 deliveries were performed; the rate of caesarean sections was $14 \%$. A neonatal unit with six thermal cots is available since 2011, providing pharmacological therapy and kangaroo mother care therapy, although there is no possibility of mechanical ventilation. An emergency referral system deals with complications arising at primary care facilities. The SLH has an $\mathrm{MWH}$ which is a corrugated iron roofed and brick walled structure with 27 beds in two rooms, flushing water closet and kitchen. Admitted mothers receive a visit two times per week by a dedicated midwife coming from the maternity ward; they can always refer to the gynaecologist in case of urgent issues. During the stay, the hospital guarantees basic food supply and kitchen utensils and allows the presence of companions to take care of the pregnant women. Pregnant women living far from the hospital are usually referred to the $\mathrm{MWH}$ in case of high-risk pregnancy or false labour and when a caesarean section is envisaged or mandatory.

\section{Study design}

We conducted a monocentric, nested case-control study at the SLH in Wolisso, SWSZ, Ethiopia.

Cases were all mothers giving birth in the SLH, whose childbirth resulted in stillbirth or early neonatal death. Stillbirth was defined as a baby born with no signs of life after 28 weeks' gestation or weighing more than $1000 \mathrm{~g} .{ }^{13}$ Both macerated stillbirth (dead before the onset of labour and presenting degenerative changes) and fresh stillbirth (dead during labour or delivery) were considered..$^{13}$ Early neonatal mortality was defined as a baby born alive but dead within 7 days. ${ }^{14}$

Controls were mothers giving birth in SLH, whose childbirth resulted in a baby alive at 7 days or until hospital discharge. For each case, two controls were selected. Controls were the two mothers who followed each case on the delivery registry. ${ }^{14}$ This choice of controls was made to minimise the 
Table 1 Rate of perinatal death by admission to the maternity waiting home (MWH). Ethiopia, 2014-2017.

\begin{tabular}{lcccc}
\hline & & \multicolumn{2}{l}{ Perinatal death } & \\
\cline { 3 - 4 } & & Yes (cases) & No (controls) & P-value* \\
\cline { 3 - 4 } & & $\mathbf{n ~ ( \% )}$ & $\mathbf{n ~ ( \% )}$ & \\
\hline Access to & Yes & $51(4.3)$ & $143(6.1)$ & 0.034 \\
MWH & No & $1124(95.7)$ & $2207(93.9)$ & \\
Total & & $1175(100.0)$ & $2350(100.0)$ & \\
\hline
\end{tabular}

${ }^{*}$ In bold p-value $<0.05$.

possibility that each case and its controls received a different level of healthcare assistance during labour. ${ }^{15}$

Mothers who gave birth to both dead twins were considered as cases, considering data about the first recorded twin only. Mothers who gave birth to a dead and an alive newborn were selected as cases considering data of the dead one; by definition they could not be chosen as controls. Mothers who gave birth to both twins alive were selected as controls in case they gave birth immediately after a case and data referred to the first recorded baby. The exposure of interest was the admission to MWH before the delivery.

\section{Patient and public involvement}

Since this was a retrospective study, patients were not involved in the design or management of the study, while midwives working in $\mathrm{MWH}$ were interviewed and contributed to the design of the study and data collection. This study was designed and conducted as part of the broader 'Mothers and children first' project run by the NGO 'Doctors With Africa CUAMM' (https://www.mediciconlafrica.org/en/what-wedo/in-africa/mothers-and-children-first), whose objectives were, among others, the active empowerment of women

Table 2 Conditions related to the maternal health and to the current pregnancy in MWH users and non-users. Ethiopia, 2014-2017.

\begin{tabular}{|c|c|c|c|c|}
\hline & & Non-MWH & MWH user & P-value* \\
\hline & & $\%(n)$ & $\%(n)$ & \\
\hline Age & $\leq 24$ years & $37.2(1227)$ & $22.7(44)$ & $<0.001$ \\
\hline & $25-34$ years & $50.2(1658)$ & $56.7(110)$ & \\
\hline & $\geq 35$ years & $12.6(415)$ & $20.6(40)$ & \\
\hline Area of residence & Urban & $31.9(1063)$ & $11.9(23)$ & $<0.001$ \\
\hline & Rural & $68.1(2268)$ & $88.1(171)$ & \\
\hline Hypertensiont & & $2.3(77)$ & $2.6(5)$ & 0.804 \\
\hline Chronic diseases & & $1.3(43)$ & $1.0(2)$ & 1.000 \\
\hline Infectious diseases (except HIV/AIDS) & & $0.3(9)$ & $0.0(0)$ & 1.000 \\
\hline HIV/AIDS & & $2.0(68)$ & $1.5(3)$ & 1.000 \\
\hline Parity & $\leq 4$ born & $90.2(3005)$ & $79.4(154)$ & $<0.001$ \\
\hline & 5 born or more & $9.8(326)$ & $20.6(40)$ & \\
\hline Previous caesarean sections & None & $93.8(3125)$ & $68.0(132)$ & $<0.001$ \\
\hline & At least once & $6.2(206)$ & $32.0(62)$ & \\
\hline Previous complicated pregnancies & Negative anamnesis & $99.7(3320)$ & $96.4(187)$ & $<0.001$ \\
\hline & Positive anamnesis & $0.3(11)$ & $3.6(7)$ & \\
\hline Access to antenatal care & None & $76.1(2515)$ & $53.9(104)$ & $<0.001$ \\
\hline & At least once & $23.9(788)$ & $46.1(89)$ & \\
\hline Type of pregnancy & Single & $94.8(3158)$ & $85.6(166)$ & $<0.001$ \\
\hline & Multiple & $5.2(173)$ & $14.4(28)$ & \\
\hline Preeclampsia & & $3.1(102)$ & $6.7(13)$ & 0.011 \\
\hline Oligohydramnios & & $0.6(21)$ & $1.0(2)$ & 0.364 \\
\hline Polyhydramnios & & $1.3(43)$ & $3.6(7)$ & 0.018 \\
\hline Breech presentation & & $3.7(123)$ & $9.3(18)$ & 0.001 \\
\hline Antepartum haemorrhage & & $3.2(107)$ & $6.2(12)$ & 0.038 \\
\hline Gestational age & Pre-term/complete & $97.7(3255)$ & $96.4(187)$ & 0.221 \\
\hline & Post-term & $2.3(76)$ & $3.6(7)$ & \\
\hline
\end{tabular}

Numbers may not add to total sample size due to missing values.

*In bold $\mathrm{p}$-value<0.05.

†Systolic blood pressure $>140 \mathrm{~mm} \mathrm{Hg}$ or diastolic blood pressure $>90 \mathrm{~mm} \mathrm{Hg}$. 
Table 3 Obstetric conditions in MWH users and non-users. Ethiopia, 2014-2017.

\begin{tabular}{|c|c|c|c|}
\hline & \multirow{2}{*}{$\begin{array}{l}\text { Non-MWH } \\
\% \text { (n) }\end{array}$} & \multirow{2}{*}{$\begin{array}{l}\text { MWH user } \\
\% \text { (n) }\end{array}$} & \multirow[b]{2}{*}{ P-value } \\
\hline & & & \\
\hline Shoulder dystocia & $0.5(17)$ & $0.5(1)$ & 1.000 \\
\hline Other dystocia & $4.6(153)$ & $7.2(14)$ & 0.114 \\
\hline Eclampsia & $0.7(24)$ & $0.0(0)$ & 0.640 \\
\hline Premature rupture of membranes & $10.8(359)$ & $2.1(4)$ & $<0.001$ \\
\hline Head stuck & $0.5(18)$ & $1.0(2)$ & 0.302 \\
\hline Cephalopelvic Disproportion (CPD) & $2.5(84)$ & $0.5(1)$ & 0.089 \\
\hline Obstructed labour & $0.6(19)$ & $0.0(0)$ & 0.622 \\
\hline Placental abruption & $0.9(31)$ & $1.5(3)$ & 0.432 \\
\hline Nuchal cord (or Cord-Around-the Neck) & $1.4(48)$ & $0.5(1)$ & 0.521 \\
\hline Umbilical cord/hand prolapse & $2.6(85)$ & $1.5(3)$ & 0.632 \\
\hline Placenta praevia & $0.9(31)$ & $4.1(8)$ & 0.001 \\
\hline \multicolumn{4}{|l|}{ Type of delivery } \\
\hline Spontaneous vaginal delivery & $68.4(2276)$ & $48.5(94)$ & $<0.001$ \\
\hline Breech birth & $6.3(209)$ & $10.8(21)$ & \\
\hline Forceps/Windy & $6.8(227)$ & $6.7(13)$ & \\
\hline Caesarean & $13.8(458)$ & $30.4(59)$ & \\
\hline Destructive & $4.8(159)$ & $3.6(7)$ & \\
\hline \multicolumn{4}{|l|}{ Presence of meconium } \\
\hline Absent & $96.0(3199)$ & $99.0(192)$ & 0.033 \\
\hline At least grade I & $4.0(132)$ & $1.0(2)$ & \\
\hline
\end{tabular}

Numbers may not add tototal sample size due to missing values.

*In bold $p$-value $<0.05$.

within the community and the increase of technical skills among midwives.

The preliminary results of the project, both on care and research activities, are presented periodically, usually in the form of dissemination workshop, inviting all stakeholders involved, including representatives of the population and local health authorities. In addition, we also intend to spread the main results of this study to community midwives and healthcare professionals working mostly in remote and rural areas, with the aim of providing them with further evidence to refer pregnant women to the $\mathrm{MWH}$ in case of real need and trying to overcome social and economic barriers that often discourage referral and admission to the MWH. Healthcare workers in these areas have a crucial role in promoting patient and public involvement.

This modus operandi is not new in this context: community awareness and mobility interventions have already been implemented with the aim of constantly increasing knowledge and, finally, access to health services, especially for the most disadvantaged populations. The community awareness has been steadily improved over the previous 6 years, through the provision of various demand creation activities, including pregnant women's forums to discuss birth preparation, safe and free institutional childbirth; mass mobilisation events; awareness campaigns on health education, HIV and tuberculosis prevention; counselling and screening for cervical and breast cancer prevention and counselling for including income-generating activities in women.

\section{Data collection}

We collected demographic characteristics and basic anamnestic data about mothers and newborns, considering variables investigated in past studies, as well as conditions that might arise as potential indications for admission to the MWH in our specific context. We collected data on (1) pregnancy-related conditions, (2) obstetric conditions and (3) neonatal conditions. A review of the delivery register, the hospital electronic inpatient database, the neonatal admission charts and the MWH register was undertaken, considering data collected between January 2014 and December 2017. All sources were linkable through the unique admission code that each mother received at admission. Data collection followed the Strengthening the Reporting of Observational Studies in Epidemiology statement for observational studies (see online supplemental appendix for the checklist of items included).

\section{Sample size}

A sample size of 3240 mothers (of which 1080 cases) was required to detect a probability of exposure in cases of at least $3.5 \%$, assuming a $5.8 \%$ probability of exposure in controls, a case:control ratio of 1:2, an $80 \%$ power and a $5 \%$ significance 
level. The assumption of $5.8 \%$ probability of exposure was set according to data shown in the SLH annual report. ${ }^{16}$

\section{Data analysis}

Data were summarised in contingency tables of frequencies and proportions. A preliminary bivariate analysis was conducted to identify differences between the group exposed to the MWH and the non-exposed group. Fisher's exact test was used to assess the association with potential confounding factors. We performed a crude analysis to establish the association between perinatal mortality (entered as dependent variable) and the access to $\mathrm{MWH}$ (as independent variable) for the total sample using logistic regression. All the other investigated variables were included in the multivariate logistic regression to assess this association after adjusting for potential confounders. The variables Apgar at $5 \mathrm{~min}$ and birth weight were not included in the model since strongly correlated with outcome mortality, of which may be considered as proxy - the correlation coefficient phi for nominal variables was statistically significant $(\mathrm{p}<0.001)$ for both pairs. Unadjusted and adjusted ORs (AORs), 95\% CIs and $\mathrm{p}$ values are reported. The level of significance was set at a $p$ value of $<0.05$.

Finally, to further investigate the potential confounding effect of a selection bias, we identified the triplets (one case and two controls) with at least a twin (either the case or one of the controls) and performed a sensitivity analysis by excluding these triplets. Statistical analyses were performed using STATA software, V.12.1 (StataCorp, College Station, Texas, USA).

\section{RESULTS}

Overall, 3525 mothers were included in the study, of which 1175 cases and 2350 controls. The proportion of missing data ranged between $0.0 \%$ and $0.9 \%$ based on variables investigated. As shown in table 1, $4.3 \%$ of cases and $6.1 \%$ of controls were admitted to the MWH $(\mathrm{p}=0.034)$.

MWH users used to hail from rural areas in a significantly larger proportion compared with non-users $(88.1 \%$ vs $68.1 \%, \mathrm{p}<0.001$ ), as shown in table 2. Mothers attending the MWH were usually older $(\mathrm{p}<0.001)$ and the proportion of grand multiparas was twice higher than the counterpart
(20.6\% vs 9.8\%, $\mathrm{p}<0.001)$. MWH mothers had more often a history of complicated pregnancies $(3.6 \%$ vs $0.3 \%, \mathrm{p}<0.001)$ and caesarean sections $(32.0 \%$ vs $6.2 \%, \mathrm{p}<0.001)$; moreover, about half of them underwent at least one antenatal care (ANC) visit (46.1\%) compared with $23.9 \%$ of mothers who did not attend the MWH $(\mathrm{p}<0.001)$. Among MWH users, the prevalence of pre-eclampsia, polyhydramnios, breech presentation and antepartum haemorrhage was significantly higher (see table 2).

While the occurrence of premature rupture of membranes $(2.1 \%$ vs $10.8 \%, \mathrm{p}<0.001)$ and $\geq 1$ grade meconium ( $1.0 \%$ vs $4.0 \%, \mathrm{p}=0.033)$ was lower in $\mathrm{MWH}$ users, the prevalence of placental abruption was higher ( $4.1 \%$ vs $0.9 \%, p<0.001)$. The proportion of caesarean sections $(30.4 \%$ vs $13.8 \%)$ and breech deliveries $(10.8 \%$ vs $6.3 \%)$ was higher than non-users. While no difference was detected in the occurrence of neonatal malformations in the two groups, the percentage of newborns with 5 min Apgar $\geq 7$ was higher in $\mathrm{MWH}$ mothers $(72.7 \%$ vs $64.5 \%, \mathrm{p}=0.020)$, as well as babies weighing $\geq 2500 \mathrm{~g}$ (80.4\% vs $72.5 \%, \mathrm{p}=0.016)$ (tables 3 and 4).

The crude analysis showed a protective effect of the MWH towards perinatal mortality (unadjusted $\mathrm{OR}=0.700$; 95\% CI: 0.505 to 0.972 ). The magnitude of this protective effect increased after adjusting for potential confounders (AOR $=0.452 ; 95 \%$ CI: 0.293 to 0.698 ) (table 5 ).

After having excluded 189 triplets with at least a twin, the AOR showed a slight decrease in the magnitude of the protective effect of the MWH towards perinatal mortality, without, however, losing its statistical significance $(\mathrm{AOR}=0.550 ; 95 \%$ CI: 0.330 to 0.917$)$.

\section{CONCLUSION}

To our knowledge, this study is the first case-control study that evaluates the effectiveness of MWHs in reducing perinatal mortality in a low-to-middle-income country. The risk of perinatal mortality among MWH users was less than half of non-users, showing the effectiveness of this strategy in reducing perinatal mortality.

Table 4 Neonatal characteristics in MWH users and non-users. Ethiopia, 2014-2017.

\begin{tabular}{|c|c|c|c|c|}
\hline & & Non-MWH & MWH user & \\
\hline & & $\%(n)$ & $\%(n)$ & P-value* \\
\hline Malformations & & $3.2(105)$ & $4.6(9)$ & 0.291 \\
\hline Sex of the born & Female & 46.0 (1528) & $53.1(103)$ & 0.064 \\
\hline & Male & $54.0(1792)$ & 46.9 (91) & \\
\hline APGAR at $5 \mathrm{~min}$ & $7-10$ & $64.5(2146)$ & 72.7 (141) & 0.020 \\
\hline & $0-6$ & 35.5 (1182) & $27.3(53)$ & \\
\hline Birth weight & $\geq 2500 \mathrm{gr}$ & 72.5 (2416) & 80.4 (156) & 0.016 \\
\hline & $<2500 \mathrm{gr}$ & $27.5(915)$ & $19.6(38)$ & \\
\hline
\end{tabular}

Numbers may not add tototal sample size due to missing values.

${ }^{*}$ In bold $p$-value $<0.05$. 
Table 5 Logistic regressions. Risk of perinatal mortality. Odds ratios, 95\% confidence intervals, p-values. Ethiopia. Years 2014-2017.

\begin{tabular}{|c|c|c|c|c|c|c|}
\hline & Unadjusted OR & $95 \% \mathrm{Cl}$ & P-value* & Adjusted OR† & $95 \% \mathrm{Cl}$ & P value* \\
\hline Access to MWH (all cases) & 0.700 & 0.505 to 0.972 & 0.033 & 0.452 & 0.293 to 0.698 & $<0.001$ \\
\hline $\begin{array}{l}\text { Access to MWH (excluding } \\
\text { triplets with at least a twin) }\end{array}$ & 0.764 & 0.528 to 1.104 & 0.152 & 0.550 & 0.330 to 0.917 & 0.022 \\
\hline
\end{tabular}

*In bold p-value $<0.05$.

†The regression analysis was adjusted for all variables showed in tables 2-4.

This result is comparable with previous studies from Ethiopia $^{10-12}$ and other resource-limited settings, ${ }^{17-20}$ although not all of them demonstrated a significant reduction in the risk of perinatal deaths in MWH users. ${ }^{21} 22$ Most of the previous studies were cross-sectional, conducted on a limited population and only few of them adjusted for confounding factors. In the document Recommendations on health promotion interventions for maternal and newborn health, the WHO has expressed the need for further studies with a more robust design that would measure the contribution of MWHs within a package of interventions aimed at increasing the access to skilled care. ${ }^{6}$ Our study relies on a case-control design, and a considerable number of maternal, obstetrical and neonatal factors were included in the analysis as confounding variables. Indeed, many disorders associated with stillbirths often coexist, $^{23}$ and adjustment for these factors is essential to understand the role of a specific intervention. In addition, we evaluated the effectiveness of the MWH including also twin births. In previous studies, twin births have often been ruled out from the analysis ${ }^{18}$ or findings arising from this subgroup have not been discussed ${ }^{24}$ probably because of implications from a potential selection bias or the complexity of handling this variable. However, the suspicion of a multiple pregnancy is one of the most frequent criteria for admission to the MWH and a well-known risk factor for perinatal death. ${ }^{25}$ Considering this, the evaluation of the effectiveness of $\mathrm{MWH}$ in this category appears even more essential. To handle the risk of a potential selection bias, we decided to perform a sensitivity analysis. Our findings clearly showed how the MWH acted as a significantly protective factor from perinatal mortality either including multiple pregnancies or not.

Compared with non-MWH mothers, MWH users were older, came from rural areas, had a worse obstetric history, higher parity and a higher number of previous caesarean sections. Moreover, MWH users showed a significantly higher prevalence of all risk factors which are detectable during pregnancy (except for oligohydramnios), while the prevalence of maternal pre-existing conditions was similar in the two groups. Based on this set of information, a higher perinatal mortality would be expected in this group ${ }^{26}$ but our findings show how MWHs are associated with a significant reduction in perinatal death. Our main finding, together with data on risk factors detectable during pregnancy, conforms as regards the risk of a selection bias described in past research. ${ }^{7}$ Nevertheless, the presence of peripheral health centres and the ambulance transport service may increase the proportion of women who go directly to the hospital, without being admitted to the MWH, so that women in this catchment area may have more favourable outcome compared with other contexts. However, the availability of ambulance transport has to be considered complementary to the MWH because obstetric emergencies may arise during labour or delivery even in women without a previously detected high-risk pregnancy. ${ }^{5}$

This study also suggests that the MWH is effective in selecting women who actually need additional medical assistance. The WHO, indeed, set as a priority the conduction of studies able to show whether the MWH should be recommended in a specific subset of women sharing potential risk factors as vulnerability, high distance to healthcare facilities or peculiar obstetric risk. ${ }^{6}$ Despite a higher prevalence of conditions detected prenatally, MWH users show a similar or even lower prevalence of obstetric complications (except for placenta praevia). A possible explanation may rely on a more timeliness intervention as complications occur, which enables the healthcare professionals to have a wider choice of therapeutic options. For instance, among MWH users, the proportion of caesarean section deliveries was more than twice higher than in non-users. ${ }^{5}$ Definitely, this aspect is also reflected in better neonatal outcomes in terms of both Apgar score and birth weight for MWH users. Our study can rely on a plenty of variables investigated, allowing to identify the profile of women at risk who could actually benefit from the admission to $\mathrm{MWH}$. Our results, together with evidence provided in other Ethiopian settings, may be useful for drafting priority criteria for the admission to MWHs on a national basis. $^{27}$

In Ethiopia, faith-based organisations have pioneered the construction of the first MWHs in the late 1980s. Slowly, others were built, some under the aegis of the ministry of health, but in 2012 only nine facilities, including Wolisso Hospital, were provided with an MWH. ${ }^{27}$ In 2016 in Ethiopia, $52 \%$ of health facilities were provided with an MWH. ${ }^{28}$ The main aim of this strategy in the struggle towards the reduction of perinatal mortality in Ethiopia is to bridge the geographical gap in obstetric care between rural and urban areas and areas with poor access to healthcare facilities. Once labour starts, women would rapidly move to the health facility so that they can be assisted by a skilled birth attendant. ${ }^{28}$ In addition, during their stay, mothers receive healthy and nutritious food-free of charge for mothers, provided by the community - and they are given specific advice on any problems that may occur in the days immediately following delivery. $^{28}$ 
Our results need necessarily to be contextualised. The hospital involved in the study shows peculiar featuressurgical capacity and associated competencies; private ownership; programmes funded by external donors; the presence of HIV treatment programmes in the healthcare-which are known to be associated with higher quality standard of services implemented and, ultimately, lower perinatal mortality: indeed, secondary care facilities-regardless of the delivery volume-appear to be better equipped to provide better care for women experiencing complications during the delivery than primary care facilities. ${ }^{5}$

This study has several strengths. First, it stands out for being the first case-control study investigating the effectiveness of MWHs and handles a high number of variables, which allowed us to adjust for many covariates that could potentially confound our association. These features meet the WHO recommendations for an improvement of scientific evidence in similar contexts. ${ }^{6}$ Second, the sample size is relatively large and all cases occurring in the study period were included. Only few other studies investigating the effectiveness of the MWH showed a larger or similar sample size. ${ }^{11} 18$ Third, the completeness of variables investigated is very high $(99.1 \%$ or more, depending on the variable at issue). In low-income and middle-income countries, archives are usually paper based and not well stored. Our decision to conduct a nested case-control study rather than a retrospective cohort study relies on this: in the absence of an integrated electronic health records management system, we preferred to collect all available data on a sample of controls rather than including the whole cohort. Lastly, we were the first to perform a sensitivity analysis which allowed us to take into account-and assess-the effectiveness of $\mathrm{MWH}$ on perinatal mortality also in case of twin pregnancies.

The study has also some limitations. We did not retrieve data on the socioeconomic status of the mothers at the individual level. Two recent studies conducted in Ethiopia showed that MWH users were on average less educated and poorer than women admitted directly to hospital. ${ }^{24}{ }^{29} \mathrm{In}$ rural areas, the population is poorer and education lower, and maternal lower education and economic hardship were shown to be associated with higher perinatal mortality. ${ }^{15}$ However, not all of the most recent Ethiopian studies agree on the role of these factors on perinatal mortality; quite the opposite, all show that the number of previous deliveries and previous obstetric complications make the greatest contribution, and among the socioeconomic determinants, the residence in a rural area shows the greatest association with perinatal mortality. ${ }^{30-32}$ These three factors are all known during pregnancy and may act as crucial indications for admission to the MWH. In addition to this, our study is monocentric; although a detailed description of the context may allow for comparisons between situations with a similar—or, by contrast, different—background, the extendibility of our findings remains limited, suggesting the need for multicentre researches.

In conclusion, our findings show how MWHs appear to be able to reduce perinatal mortality by $55 \%$. Our study is the first case-control study to estimate the effect of MWH in reducing perinatal mortality, making a substantial contribution in improving the quality of evidence as advocated by the scientific community and the major health authorities at the global level. The MWH is effective in reducing perinatal mortality although $\mathrm{MWH}$ users show more risk factors, some of which-including twin pregnancy-are clearly involved in driving the decision whether getting admitted to MWH. Our findings support the decision to invest in MWHs, providing pregnant women with higher quality and more comprehensive healthcare. However, to meet this target, efforts should be addressed also in providing quality ANC in peripheral primary care clinics, where properly trained healthcare professionals may recognise the occurrence of risk factors that may pose an indication for admission to the MWH. Although our findings may be extended to contexts with a background similar to that described in this study, our research lays the basis for a legitimate need for multicentre studies that would act as a driving force for a further generalisation of this achievement.

Contributors TDZ, GP and CB conceived the concept. TDZ and CB designed the protocol. CR, AT and GA oversaw the data collection and monitoring. MF and MS performed statistical analyses. TDZ, MF and CB wrote the initial draft of the paper. FM contributed to the study design and data interpretation. All authors reviewed and approved the final draft of the paper.

Funding The authors have not declared a specific grant for this research from any funding agency in the public, commercial or not-for-profit sectors.

Competing interests None declared.

Patient consent for publication Not required.

Ethics approval The study complied with the Helsinki Declaration. Ethical approval was obtained from the ethical committee of the Saint Luke Hospital. Personal data were processed in an anonymous and aggregate form.

Provenance and peer review Not commissioned; externally peer reviewed.

Data availability statement Data are available upon request.

Supplemental material This content has been supplied by the author(s). It has not been vetted by BMJ Publishing Group Limited (BMJ) and may not have been peer-reviewed. Any opinions or recommendations discussed are solely those of the author(s) and are not endorsed by BMJ. BMJ disclaims all liability and responsibility arising from any reliance placed on the content. Where the content includes any translated material, BMJ does not warrant the accuracy and reliability of the translations (including but not limited to local regulations, clinical guidelines, terminology, drug names and drug dosages), and is not responsible for any error and/or omissions arising from translation and adaptation or otherwise.

Open access This is an open access article distributed in accordance with the Creative Commons Attribution Non Commercial (CC BY-NC 4.0) license, which permits others to distribute, remix, adapt, build upon this work non-commercially, and license their derivative works on different terms, provided the original work is properly cited, appropriate credit is given, any changes made indicated, and the use is non-commercial. See: http://creativecommons.org/licenses/by-nc/4.0/.

\section{ORCID iDs}

Teresa Dalla Zuanna http://orcid.org/0000-0003-1244-404X

Marco Fonzo http://orcid.org/0000-0002-9561-0711

\section{REFERENCES}

1 United Nations. Transforming our world: the 2030 agenda for sustainable development. Available: https://sustainabledevel opment.un.org/content/documents/21252030\%20Agenda\%20for\% 20Sustainable\%20Development\%20web.pdf

2 Alliance for Maternal and Newborn Health Improvement (AMANHI) mortality study group. Population-based rates, timing, and causes of maternal deaths, stillbirths, and neonatal deaths in South Asia 
and sub-Saharan Africa: a multi-country prospective cohort study. Lancet Glob Health 2018;6:e1297-308.

3 Madhi SA, Briner C, Maswime S, et al. Causes of stillbirths among women from South Africa: a prospective, observational study. Lancet Glob Health 2019;7:e503-12.

4 Cooper P. Strategies to reduce perinatal mortality. Lancet Glob Health 2016;4:e6-7.

5 Kruk ME, Leslie HH, Verguet S, et al. Quality of basic maternal care functions in health facilities of five African countries: an analysis of national health system surveys. Lancet Glob Health 2016;4:e845-55.

6 World Health Organization. Who recommendations on health promotion interventions for maternal and newborn health, 2015. Available: http:// www.ncbi.nlm.nih.gov/books/NBK304983/ [Accessed 6 Dec 2018].

7 van Lonkhuijzen L, Stekelenburg J, van Roosmalen J. Maternity waiting facilities for improving maternal and neonatal outcome in low-resource countries. Cochrane Database Syst Rev 2012;10:CD006759.

8 Buser JM, Lori JR. Newborn outcomes and maternity waiting homes in low and middle-income countries: a scoping review. Matern Child Health J 2017;21:760-9.

9 Central Statistical Agency (CSA), ICF. Ethiopia demographic and health survey 2016, 2017

10 Poovan P, Kifle F, Kwast BE. A maternity waiting home reduces obstetric catastrophes. World Health Forum 1990;11:440-5.

11 Kelly J, Kohls E, Poovan P, et al. The role of a maternity waiting area (MWA) in reducing maternal mortality and stillbirths in high-risk women in rural Ethiopia. BJOG 2010;117:1377-83.

12 Tiruneh GT, Taye BW, Karim AM. Maternity waiting homes in Rural Health Centers of Ethiop: The situation, women's experiences and challenges. Ethiop J Health Dev; 10.

13 WHO. Making every baby count. audit and review of stillbirths and neonatal deaths, 2016.

14 Musafili A, Essén B, Baribwira C, et al. Social equity in perinatal survival: a case-control study at hospitals in Kigali, Rwanda. Acta Paediatr 2015;104:1233-40.

15 McClure EM, Pasha O, Goudar SS, et al. Epidemiology of stillbirth in low-middle income countries: a global network study. Acta Obstet Gynecol Scand 2011;90:1379-85.

16 Saint Luke Hospital. Annual report of St. Luke Catholic hospital and College of nursing and midwifery, 2017. Available: http://stlukecathol ichospital.org/2017\%20Annual\%20Report.pdf [Accessed 11 Dec 2018].

17 Millard P, Bailey J, Hanson J. Antenatal village stay and pregnancy outcome in rural Zimbabwe. Cent Afr J Med 1991;37:1-4.

18 Chandramohan D, Cutts F, Millard P. The effect of stay in a maternity waiting home on perinatal mortality in rural Zimbabwe. $J$ Trop Med Hyg 1995;98:261-7.
19 Tumwine JK, Dungare PS. Maternity waiting shelters and pregnancy outcome: experience from a rural area in Zimbabwe. Ann Trop Paediatr 1996;16:55-9.

20 Lori JR, Munro ML, Rominski S, et al. Maternity waiting homes and traditional midwives in rural Liberia. Int $J$ Gynaecol Obstet 2013;123:114-8.

21 van Lonkhuijzen L, Stegeman M, Nyirongo R, et al. Use of maternity waiting home in rural Zambia. Afr $J$ Reprod Health 2003;7:32.

22 Singh K, Speizer I, Kim ET, et al. Reaching vulnerable women through maternity waiting homes in Malawi. Int J Gynecol Obstet 2017; 136:91-7.

23 Lawn JE, Blencowe $\mathrm{H}$, Waiswa $\mathrm{P}$, et al. Stillbirths: rates, risk factors, and acceleration towards 2030. Lancet 2016;387:587-603.

24 Braat F, Vermeiden T, Getnet G, et al. Comparison of pregnancy outcomes between maternity waiting home users and non-users at hospitals with and without a maternity waiting home: retrospective cohort study. Int Health 2018;10:47-53.

25 Andargie G, Berhane Y, Worku A, et al. Predictors of perinatal mortality in rural population of northwest Ethiopia: a prospective longitudinal study. BMC Public Health 2013;13:168.

26 Bishop D, Dyer RA, Maswime S, et al. Maternal and neonatal outcomes after caesarean delivery in the African surgical outcomes study: a 7-day prospective observational cohort study. Lancet Glob Health 2019;7:e513-22.

27 Gaym A, Pearson L. Maternity waiting homes in Ethiopia -three decades experience. 12, 2012.

$28 \mathrm{EPHI}, \mathrm{FMoH}, \mathrm{AMDD}$. Ethiopian emergency obstetric and newborn care (EmONC) assessment 2016: final report, 2017. Available: https://www.ephi.gov.et/images/pictures/download2010/FINALEmONC-Final-Report-Oct25-2017.pdf [Accessed 30 Aug 2020].

29 Fogliati P, Straneo M, Mangi S, et al. A new use for an old tool: maternity waiting homes to improve equity in rural childbirth care. results from a cross-sectional hospital and community survey in Tanzania. Health Policy Plan 2017;32:1354-60.

30 Yirgu R, Molla M, Sibley L. Determinants of neonatal mortality in rural Northern Ethiopia: a population based nested case control study. PLoS One 2017;12:e0172875.

31 Fenta SM, Biresaw HB, Fentaw KD. Risk factor of neonatal mortality in Ethiopia: multilevel analysis of 2016 demographic and health survey. Trop Med Health 2021;49:14.

32 Basha GW, Woya AA, Tekile AK. Determinants of neonatal mortality in Ethiopia: an analysis of the 2016 Ethiopia demographic and health survey. Afr Health Sci 2020;20:715-23. 